\title{
Coping styles and vulnerability to eating disorders in adolescent girls, by age
}

\author{
Estrategias de afrontamiento y vulnerabilidad a los trastornos de la conducta \\ alimentaria, en chicas adolecentes, en función de la edad
}

\author{
Natàlia Mas \\ PhD Student, Department of Personality, Assessment, and Psychological Treatment, \\ Faculty of Psychology, University of Barcelona, Barcelona, Spain
}

\begin{abstract}
Adela Fusté
Associate Professor, Department of Personality, Assessment, and Psychological Treatment, Faculty of Psychology, University of Barcelona, Barcelona, Spain

\section{Eugeni García-Grau}

Associate Professor, Department of Personality, Assessment, and Psychological Treatment, Faculty of Psychology, University of Barcelona, Barcelona, Spain

\section{Arturo Bados}

Associate Professor, Department of Personality, Assessment, and Psychological Treatment, Faculty of Psychology, University of Barcelona, Barcelona, Spain
\end{abstract}

(Rec: 20 marzo 2014 / Acept: 1 julio 2015)

\begin{abstract}
The main goal of the study is to explore the relationship between coping styles and vulnerability to eating disorders in a sample of adolescent girls, according to their age. The sample comprises 1396 girls, aged 13 to 18, who completed the Eating Disorders Inventory-3 (EDI-3) and the Adolescent Coping Scale (ACS). The regression analysis shows that the coping strategy most closely linked to the likelihood of developing an ED in all age groups is Intropunitive Avoidance. The scales of the Intropunitive Avoidance dimension that have the most explanatory power are Tension Reduction and Self-Blame. Girls aged 13 and 17 are identified as the highest risk groups. Physical and social changes are proposed as the hypothetical explanation for the difference between age groups. Emphasis is placed on the need for specific prevention programs for adolescents, particularly those at high risk.

Keywords: coping style, eating disorder, adolescence, EDI-3, risk factors.
\end{abstract}

\section{Resumen}

El objetivo principal del estudio es explorar la relación entre estilos de afrontamiento y vulnerabilidad a trastornos de alimentación en una muestra de chicas adolescentes, según su edad. La muestra está compuesta por 1396 chicas de entre 13 y 18 años, que respondieron a los cuestionarios Eating Disorders Inventory-3 (EDI-3) y el Adolescent Coping Scale (ACS). Los análisis de regresión muestran que la estrategia de afrontamiento más relacionada con el riesgo de sufrir TCA es la Huída Intropunitiva, en todas las edades. Las escalas de la dimensión Huida Intropunitiva con mayor poder explicativo son Reducción de la Tensión y Autoinculparse. Las chicas de 13 y 17 años son los grupos identificados de mayor riesgo. Los cambios físicos y sociales se presentan como una explicación hipotética para la diferencia entre grupos de edad. Se enfatiza en la necesidad de programas de prevención específicos para adolescentes, especialmente aquellos con mayor riesgo.

Palabras clave: estilo de afrontamiento, trastorno de la alimentación, adolescencia, EDI-3 y factores de riesgo

Correspondence: Natàlia Mas nmastobia@copc.cat, 


\section{Introduction}

Several studies indicate that mental health problems have a very high prevalence and produce the greatest economic burden among chronic diseases. Indeed, a report by the World Economic Forum (WEF) warned that the failure to address mental illness could lead to an expenditure of 16 billion dollars over the next two decades (Bloom et al., 2011). In this context, several authors and organizations such as UNICEF emphasize the importance of prevention in the mental health area, especially in childhood and adolescence (Collins et al., 2011; UNICEF, 2011).

The World Health Organization (OMS, 2004) reports that, in developed countries, Eating Disorders (ED) have increased over the past 50 years, reaching prevalence rates of $0.5-1 \%$ for anorexia nervosa, $0.9-4.1 \%$ for bulimia nervosa, and $5-13 \%$ for partial syndromes of ED. Similarly, several studies have found eating-related risk behaviors in adolescents in Europe and North America (Ballester \& Guirado, 2003; López-Guimerà, Neumark-Sztainer, Hannan, Fauquet, Loth \& Sánchez-Carracedo, 2012) and Central America (Moreno \& Ortiz, 2009). The international report Health Behaviour in School-Aged Children (Moreno et al., 2008) indicated that in Spain, $14.8 \%$ of the 21,811 participants aged 11 to 18 did not have breakfast on weekdays, $15.5 \%$ of girls admitted that they were dieting or doing something else to lose weight, and $30.4 \%$ of girls said that although they were not dieting they thought they should lose some weight. These results are confirmed in the 2012 version of the study, with something of an upward trend (OMS, 2012a).

Unfortunately, the outcomes of prevention programs for eating disorders have so far proved unsatisfactory (Austin, 2000; Yager \& O'dea, 2008). A meta-analysis by Stice, Shaw, and Marti (2007), which provided data on effect size, found that only two of the 51 prevention programs analyzed (3.92\%) obtained effect sizes of 0.30 or more on at least two of the six variables at follow-up. This highlights the need for further research on risk and protective factors in order to guide the design of effective programs.

Over the last 30 years most of the studies examining the relationship between coping and eating disorders have focused on the analysis of clinical populations or of clinical samples compared with the general population (Fitzsimmons \& Bardone-Cone, 2010; Lobera, Estébanez, Fernández, Bautista \& Garrido, 2009). In fact, our literature search revealed that since the 1980 s until today only 22 studies have examined this relationship in the general population (Ball \& Lee, 2002; Lee, Greening \& Stoppelbein, 2007). Whatever the case, the vast majority of studies, whether conducted with clinical samples or in the general population, agree that there is a relationship between maladaptive coping styles and the risk of developing an ED.

Given this relationship, and the fact that adolescence is one of the periods associated with a higher risk of eating disorder onset, it is surprising that there are only eleven studies of the general adolescent population. Of these, one was carried out with males (García-Grau, Fusté, Miró, Saldaña \& Bados, 2004), only three address the age range from 13 to 18 years, (Hasking, 2006; Sierra \& Lemos, 2008; Sierra-Baigrie, Lemos-Giráldez, Paino \& Fonseca-Pedrero, 2012) and all except two (Pamies \& Quiles, 2012; SierraBaigrie et al., 2012) are based on relatively small samples, analyzing a maximum of 417 participants (Fryer, Waller \& Kroese, 1997; García-Grau, Fusté, Miró, Saldaña \& Bados, 2002; Hernández-Cortés \& Londoño, 2013; Sim \& Zeman, 2006; Halvarsson-Edlund, Sjödén \& Lunner, 2008; Huon et al., 1999). Moreover, we have not found any studies that analyze possible differences in coping and vulnerability to eating disorders in relation to age. However, as the report entitled Programming for health and adolescent development (OMS, 1999, p.15) states: "Adolescents are neither children nor adults, though they share some of the characteristics of both groups. Furthermore, they are not a homogeneous group; their needs vary with their stages of development and life circumstances." In this regard, the WHO notes the importance of providing mental health care for adolescents from 13 years old, as well as the need to take gender differences into account (OMS, 2011, 2012b).

In light of the above we believe it is essential not only to identify the differences in risk factors according to age and gender, but also to design prevention programs ad hoc, that is, tailoring them to the specific characteristics of their target population. Consequently, the objectives of this study are: a) to replicate, with a larger sample (over 1000 participants aged between 13 and 18) the study of García-Grau et al. (2002); and b) to analyze the relationship between coping styles and vulnerability to eating disorders in the general population of teenage girls, doing so according to their age.

\section{Method}

\section{Participants}

The initial sample comprised 1571 female students from 21 secondary schools in Catalonia (private, state, and statesubsidized schools). Following the recommendations of the 
reference manuals of the administered questionnaires, 175 participants were eliminated, resulting in a final sample of 1396 adolescent girls aged between 13 and 18 years $(\mathrm{X}=$ 15.6, $\mathrm{SD}=1.4)$.

Procedure

In order to recruit participants a number of secondary schools in major cities of Catalonia were contacted, explaining the purpose of the study. After receiving authorization from the school, a date was set for questionnaire administration and informed consent was requested. Participants completed the questionnaire in their classrooms and were guaranteed total anonymity. The study was reviewed and approved by the Institutional Review Board of the University of Barcelona.

Measures

For this study we used the Spanish adaptation of two questionnaires: the Adolescent Coping Scale (ACS, Frydenberg \& Lewis, 1997) and the Eating Disorder Inventory-3 (EDI3, Garner, 2010).

The ACS is designed to assess strategies used by adolescents (12 to 18 years) to cope with problems. It comprises 80 items, one of which is open-ended, and allows the assessment of 18 different types of coping strategies that have been identified conceptually and empirically.

Item scores are based on a 5-point Likert scale ranging from 1 ("This never happens to me" or "I never do it") to 5 ("This very often happens to me" or "I do it very often"). Although our participants responded to all items, the openended question was not taken into account for the analysis.

In ACS' Spanish adaptation the 18 scales are grouped into four broad dimensions: (1) Positive and effortful action (APE), which includes scales related to appropriate problem-solving strategies; (2) Intropunitive Avoidance (HUI), reflecting a style characterized by avoidance of problems and maladaptive coping in relation to the emotions they generate. This dimension includes the scales Not Coping (Na), Tension Reduction (Rt), and Self-Blame (Cu). (3) Hedonist-positive action (APH), which refers to problem-avoidance strategies, but with an adaptive control of the emotions they generate; and (4) Introversion (INT) which is characterized by strategies based on avoiding social support to solve problems.

Reliability of the different scales in our sample is adequate, with coefficients of internal consistency (Cronbach's alpha) ranging between 0.71 and 0.75 .

The EDI-3 consists of 12 scales that assess psychological, behavioral, and affective characteristics associated with eating disorders, and it yields six composite scores. The inventory comprises 91 items which participants answer using a 5-point Likert scale ranging from 0 (never) to 5 (always). Factor analysis of raw scores on the questionnaire identified two broad dimensions: (1) Psychological Scales, which assess psychological constructs that are conceptually relevant to the development and maintenance of ED; and (2) the Eating Disorder Risk Scales, comprising Drive for Thinness (DT), Bulimia (B), and Body Dissatisfaction (BD).

The inventory also includes three validity scales: Inconsistency, Infrequency, and Negative Impression.

Reliability of the different scales is adequate in our sample, with coefficients of internal consistency (Cronbach's alpha) ranging between 0.80 and 0.83 .

For the purposes of this study we also use the factor structure proposed by García-Grau et al. (2010), since this is based on a sample of adolescent girls aged 14-19 years from the general population, very similar to that used in the present study. This factor structure comprises seven factors, with two scales that indicate a risk for eating disorder (Drive for Thinness and Body Dissatisfaction) being combined into a single factor, and the total number of items being reduced from 91 to 52 .

\section{Results}

In order to replicate the study by García-Grau et al. (2002) the entire sample is analyzed to assess the relationship between coping styles and predisposition to eating disorders in adolescent girls. Regression analyses shows that the coping strategy most strongly associated with the likelihood of developing an ED is Intropunitive Avoidance, which explains $17.2 \%$ of the variance for the Body Dissatisfaction scale, $14.4 \%$ for Bulimia, $15.4 \%$ for Drive for Thinness, and $42.1 \%$ for the total EDI-3 score.

Within the Intropunitive Avoidance dimension the scale with the highest explanatory power is Tension Reduction, explaining $13.4 \%$ of the variance for the Body Dissatisfaction scale, $12.6 \%$ for Bulimia, $13.2 \%$ for Drive for Thinness, and $32.2 \%$ for the total EDI-3 score.

In the next step we conduct an analysis of variance (ANOVA) to examine the relationship between differences in coping strategies (identified by the ACS) and the risk of eating disorders (scores on the EDI-3 risk scales), depending on age. After verifying homoscedasticity, non-parametric statistics (Mann-Whitney U) were applied whenever scores were significant on the test of homoscedasticity (Levene). As significant differences were found between age groups, post-hoc tests (Scheffé) were then applied to identify the 
age groups that differed from one another. Significance levels were corrected by the Simes method (Simes, 1986).

To analyze the variance shared between coping styles and the EDI-3 scales that were most closely related to the risk of ED, several linear regression analyses were also carried out, using as a criterion variable the scales Bulimia (B), Body Dissatisfaction (BD), and Drive for Thinness (DT) of the EDI-3, as well as the total score of the inventory. Predictor variables used were the ACS scales Positive and effortful action (APE), Intropunitive Avoidance (HUI), Hedonist-positive action (APH), and Introversion (INT). Analyses were performed following the stepwise method, setting the tolerance level at 0.60 in order to avoid or minimize redundancy among the predictor variables included in the regression equation. Residuals were analyzed and the Durbin-Watson test was applied to evaluate their possible interdependence.
The only coping strategy that shows explanatory power in all age groups and for all the variables analyzed is Intropunitive Avoidance. The percentage of variance it explains ranges from $7.7 \%$ (18 years) to $25.8 \%$ (17 years) for the Drive for Thinness scale, from $8.9 \%$ (18 years) to $18.9 \%$ (17 years) for the Bulimia scale, from $10.4 \%$ (14 years) to $27.1 \%$ (17 years) for the Body Dissatisfaction scale, and from $36 \%$ (18 years) to $51.1 \%$ (17 years) for the total EDI-3 score. Notably, in almost all cases the two age groups in which Intropunitive Avoidance explains the highest percentage of variance are 13 and 17 years.

The remaining coping strategies account for a much smaller proportion of the variance, ranging between $0.7 \%$ and $5.1 \%$; furthermore, they only show explanatory power in relation to some variables and in some age groups (see Table 1). Since Intropunitive Avoidance showed the greatest explanatory power, the analyses were then repeated, using

Table 1. Eating Disorder Risk Composite scales and total score of EDI-3 with ACS dimensions.

\begin{tabular}{|c|c|c|c|c|c|c|c|c|c|c|c|c|c|c|c|c|c|c|}
\hline & & & & $\beta$ & & & & & & $\mathrm{R}$ & & & & & & $\Delta \mathrm{R}^{2}$ & & \\
\hline $\begin{array}{ll}\text { Age } \\
\text { Scale }\end{array}$ & 13 & 14 & 15 & 16 & 17 & 18 & 13 & 14 & 15 & 16 & 17 & 18 & 13 & 14 & 15 & 16 & 17 & 18 \\
\hline BD - HUI & 0.476 & 0.328 & 0.350 & 0.423 & 0.523 & 0.333 & 0.221 & 0.104 & 0.120 & 0.177 & 0.271 & 0.104 & 0.221 & 0.104 & 0.120 & 0.177 & 0.271 & 0.104 \\
\hline $\mathrm{BD}-\mathrm{APH}$ & -0.132 & -0.203 & -0.116 & & & & & 0.140 & 0.131 & & & & & 0.036 & 0.011 & & & \\
\hline $\mathrm{BD}-\mathrm{APE}$ & & & & & & & 0.250 & & & & & & 0.029 & & & & & \\
\hline B - HUI & 0.367 & 0.326 & 0.385 & 0.411 & 0.438 & 0.309 & 0.129 & 0.102 & 0.146 & 0.166 & 0.189 & 0.089 & 0.129 & 0.102 & 0.146 & 0.166 & 0.189 & 0.089 \\
\hline $\mathrm{B}-\mathrm{APE}$ & & & & & -0.143 & & & & & & 0.204 & & & & & & 0.015 & \\
\hline B - INT & & & & & & -0.171 & & & & & & 0.112 & & & & & & 0.023 \\
\hline $\mathrm{B}-\mathrm{APH}$ & & & 0.098 & & & & & & 0.153 & & & & & & 0.007 & & & \\
\hline DT - HUI & 0.485 & 0.292 & 0.384 & 0.386 & 0.511 & 0.290 & 0.231 & 0.081 & 0.145 & 0.146 & 0.258 & 0.077 & 0.231 & 0.081 & 0.145 & 0.146 & 0.258 & 0.077 \\
\hline PT - HUI & 0.673 & 0.630 & 0.613 & 0.659 & 0.716 & 0.604 & 0.449 & 0.394 & 0.374 & 0.432 & 0.511 & 0.360 & 0.449 & 0.394 & 0.374 & 0.432 & 0.511 & 0.360 \\
\hline PT - INT & 0.189 & & 0.228 & 0.196 & 0.148 & & 0.482 & & 0.425 & 0.468 & 0.530 & & 0.033 & & 0.051 & 0.036 & 0.019 & \\
\hline PT - APH & & -0.206 & & & & & & 0.433 & & & & & & 0.039 & & & & \\
\hline
\end{tabular}

Note. BD: Body Dissatisfaction; B: Bulimia; DT: Drive for Thiness; PT: Total Score; HUI: Intropunitive Avoidance; APH: Hedonist-Positive Action; APE: Positive and Effortul Action; INT: Introversion All scores are significant $\rho<0.001$ 
Table 2. Eating Disorder Risk Composite scales and total score of EDI-3 with the scales of Intropunitive Avoidance dimension

\begin{tabular}{|c|c|c|c|c|c|c|c|c|c|c|c|c|c|c|c|c|c|c|}
\hline & & & & $\beta$ & & & & & & $\mathrm{R}$ & & & & & & $\Delta \mathrm{R}^{2}$ & & \\
\hline $\begin{array}{l}\text { Age } \\
\text { Scale }\end{array}$ & 13 & 14 & 15 & 16 & 17 & 18 & 13 & 14 & 15 & 16 & 17 & 18 & 13 & 14 & 15 & 16 & 17 & 18 \\
\hline $\mathrm{BD}-\mathrm{Cu}$ & 0.398 & 0.326 & 0.195 & 0.179 & 0.463 & & 0.153 & 0.102 & 0.120 & 0.197 & 0.211 & & 0.153 & 0.102 & 0.028 & 0.02 & 0.211 & \\
\hline BD - Rt & 0.275 & & 0.307 & 0.423 & 0.283 & & 0.211 & & 0.092 & 0.177 & 0.263 & & 0.058 & & 0.092 & 0.177 & 0.052 & \\
\hline $\mathrm{BD}-\mathrm{Na}$ & & & & & & 0.319 & & & & & & 0.095 & & & & & & 0.095 \\
\hline $\mathrm{B}-\mathrm{Na}$ & & & 0.141 & & 0.165 & & & & 0.142 & & 0.208 & & & & 0.012 & & 0.015 & \\
\hline $\mathrm{B}-\mathrm{Cu}$ & 0.305 & & 0.317 & 0.148 & & & 0.087 & & 0.098 & 0.182 & & & 0.087 & & 0.098 & 0.012 & & \\
\hline B - Rt & 0.211 & 0.305 & 0.209 & 0.415 & 0.443 & 0.341 & 0.119 & 0.089 & 0.130 & 0.170 & 0.193 & 0.110 & 0.032 & 0.089 & 0.032 & 0.170 & 0.193 & 0.110 \\
\hline $\mathrm{DT}-\mathrm{Cu}$ & 0.426 & & 0.193 & 0.156 & 0.273 & & 0.176 & & 0.143 & 0.167 & 0.239 & & 0.176 & & 0.027 & 0.014 & 0.048 & \\
\hline DT - Rt & 0.242 & 0.337 & 0.344 & 0.395 & 0.441 & 0.275 & 0.220 & 0.110 & 0.116 & 0.153 & 0.191 & 0.069 & 0.044 & 0.110 & 0.116 & 0.153 & 0.191 & 0.069 \\
\hline PT - Rt & 0.309 & 0.306 & 0.203 & 0.348 & 0.390 & 0.511 & 0.448 & 0.380 & 0.373 & 0.427 & 0.428 & 0.256 & 0.077 & 0.072 & 0.027 & 0.083 & 0.103 & 0.256 \\
\hline $\mathrm{PT}-\mathrm{Cu}$ & 0.613 & 0.418 & 0.535 & 0.588 & 0.618 & 0.335 & 0.371 & 0.308 & 0.284 & 0.344 & 0.379 & 0.344 & 0.371 & 0.308 & 0.284 & 0.344 & 0.379 & 0.088 \\
\hline $\mathrm{PT}-\mathrm{Na}$ & & 0.151 & 0.285 & & & & & 0.393 & 0.346 & & & & & 0.013 & 0.062 & & & \\
\hline
\end{tabular}

Note. BD: Body Dissatisfaction; B: Bulimia; DT: Drive for Thiness; PT: Total Score; Cu: Self-Blame; Rt: Tension reduction; Na: Not coping.

All scores are significant $\rho<0.001$

the same criterion variable (i.e. the scales associated with the risk of ED - B, BD, and DT- and the total score on the EDI-3) but introducing as predictor variables the three scales that comprise the Intropunitive Avoidance dimension: Not coping (Na), Tension Reduction (Rt), and Self-Blame (Cu).

The scales that show the greatest explanatory power are Self-Blame, with values ranging from $1.2 \%$ to $37.9 \%$, and Tension Reduction, ranging between $2.7 \%$ and $25.6 \%$. More specifically, Self-Blame is found to be the strategy that explains the highest percentage for: 1) all the variables in the 13 years age group; 2) the total EDI-3 score in all age groups, except for 18 year olds; and 3 ) Body Dissatisfaction scores in the age groups 13, 14, and 17 years old.

Tension reduction explains a greater percentage of the variance for: 1) the Drive for Thinness scale in all age groups, except 13 year olds; 2) scores on the Bulimia scale, except in the age groups 13 and 15 years old; and 3) Body
Dissatisfaction scores in the age groups 15 and 16 years old. The Not coping strategy explains a low proportion of the variance, with percentages ranging between $1.2 \%$ and 9.5\% (see Table 2).

Finally, the same analyses were conducted taking into account the factor structure proposed by García-Grau, Fusté, Mas, Gómez, Bados \& Saldaña (2010). The results are very similar: again, Intropunitive Avoidance is the only coping strategy with explanatory power in all age groups and for all the variables analyzed. Similarly, Self-Blame and Tension Reduction are the scales with the greatest explanatory power. The total explanatory power is lower, because the proposed solution has fewer items than the original. However, the explanatory power of the body factor is greater than that of the Bulimia and Body Dissatisfaction scales separately. All analysis were conducted with SPSS 14.0 version 


\section{Discussion}

The data analysis performed with the whole of the present sample confirms the results reported by García-Grau et al. (2002). Intropunitive Avoidance is found to be the coping strategy most closely linked to the likelihood of developing an eating disorder, while the Tension Reduction scale of this dimension shows the greatest explanatory power. The analysis by age group also indicates that Intropunitive Avoidance is the ACS coping strategy which shows the greatest explanatory power in all groups and for all EDI-3 analyzed variables.

These data suggest that girls who tend to avoid problems and deal in a non-adaptive way with the emotions that their problems generate are more prone to develop an ED. This finding is consistent with the results of previous studies conducted in nonclinical samples of adolescent girls in the same age range (García-Grau et al., 2002; Pamies \& Quiles, 2012; Sierra \& Lemos, 2008).

As regards the scales that comprise the Intropunitive Avoidance dimension, the results show that girls who scored high on Tension Reduction (a strategy that reflects emotional reactions to problems, for example, crying, shouting, or consuming alcohol, tobacco or drugs) have a higher risk, in most age groups, of showing behaviors associated with Drive for Thinness and Bulimia. Similarly, in most age groups, adolescents who react to problems with self-blame and guilt have a higher total score on the EDI-3, and are also more likely to be unhappy with their overall shape and the size of body regions such as the stomach, hips or thighs. This scale was not found to be relevant in the analysis of the entire sample (see Table 2).

The explanatory power of the Intropunitive Avoidance strategy increases at age 13 and 17 in relation to the Body Dissatisfaction and Drive for Thinness scales. These data probably suggest that there is a greater risk of developing an eating disorder at these ages.

The average age for the onset of menarche is 13 years (Ellis, 2004). This event marks the transition to puberty and is accompanied by major physical changes. The increase in body fat distances girls from social standards of beauty and, therefore, it may contribute to increase concern about weight and food, as well as greater body dissatisfaction (Swarr \& Richards, 1996). Tang, Yeung, and Lee (2003) studied the reactions of 1573 girls to their first menstruation and found that reported having felt embarrassed (84.9\%), annoyed $(85.8 \%)$, or worried $(74.7 \%)$. In this context, several studies have found a relationship between the onset of menarche and an increase in ED (Graber, Brooks-Gunn, Paikoff \&
Warren, 1994; Smolak, Levine \& Gralen, 1993). Moreover, menarche, as a life transition, also redefines social roles and imposes new obligations and expectations (Cavanagh, Riegle-Crumb \& Crosnoe, 2007). These changes can increase both anxiety and a concern with being socially acceptable, especially in people with maladaptive coping strategies.

The age of 17 is also associated with important life changes. Although the transition from adolescence to adulthood is nowadays somewhat blurred, it does seem that a stage comes to an end around the age of 17. In Spain, people reach the age of majority at 18 years, so those who are 17 are in their final year of being regarded, legally, as minors. In addition, secondary education ends at 17 , so people of this age must decide whether to continue with their studies or join the workforce. These changes not only involve new roles, expectations, and responsibilities, but also imply the need to relate to new social groups. Youth surveys -such as SHELL, 2006- (Kardoff \& Ohbrecht, 2008) indicate that adolescents' concerns about their status and future are a growing source of anxiety. When adolescents are confronted with new and more diverse contexts they tend to highlight the differences between themselves and others (Tanti, Stukas, Halloran \& Foody, 2011). Beck, Giddens \& Lash (1994) suggest that at this stage the body becomes a way of successfully presenting themselves to others, adding that it can be a tool for individualization. In this regard, other researchers such as Kardoff and Ohlbrecht (2008) have argued that eating disorders can be understood as a response to social changes. It is therefore reasonable to assume that at this age (i.e., 17) greater importance is again given to physical appearance, and, especially in adolescents with maladaptive coping strategies, risk behaviors associated with the development of an ED might therefore become more common.

The present research is the first to analyze the relationship between coping styles and vulnerability to eating disorders according to age. A major strength of the study is the inclusion of a broad sample covering the range of ages commonly defined as adolescence. The main limitation is the use of a cross-sectional design. Longitudinal studies are now needed to assess how many of those who score high on Intropunitive Avoidance go on to develop an ED in the medium to long term.

To conclude, the results of this study show that 1) in adolescence the greatest risk of developing an eating disorder occurs at age 13 and 17 years; and 2) the most vulnerable adolescents are those with coping styles characterized by avoidance and maladaptive strategies for dealing with the emotions that the problems generate, for example, showing 
feelings of guilt and being self-critical, and/or reactions such as crying, shouting, and consuming alcohol, tobacco, or other drugs. These data have clear implications in terms of prevention. Specifically, they highlight the need 1) to dedicate more resources to identifying those at risk among young people aged 13 and 17 years old; and 2) to develop multi-component programs that include problem-solving skills and techniques for managing emotions and enhancing self-esteem.

\section{References}

Austin, S. (2000). Prevention research in eating disorders: Theory and new directions. Psychological Medicine: A Journal Of Research In Psychiatry And The Allied Sciences, 30, 1249-1262. doi:10.1017/ S0033291799002573.

Ball, K. \& Lee, C. (2002). Psychological stress, coping, and symptoms of disordered eating in a community sample of young Australian women. International Journal of Eating Disorders, 31, 71-81. doi:10.1002 eat.1113.

Ballester, R. \& Guirado, M.C. (2003). Detección de conductas alimentarias de riesgo en niños de once a catorce años. Psicothema, 15, 556-562.

Beck, U., Giddens, A. \& Lash S. (1994). Reflexive modernization. Politics, tradition and aesthetics in the modern social order. Polity Press, Cambridge.

Bloom, D. E., Cafiero, E. T., Jané-Llopis, E., Abrahams-Gessel, S., Bloom, L. R., Fathima, S. \& Weinstein, C. (2011). The Global Economic Burden of Noncommunicable Diseases. Geneva: World Economic Forum.

Cavanagh, S. E., Riegle-Crumb, C. \& Crosnoe, R. (2007). Puberty and the Education of Girls. Social Psychology Quarterly, 70, 186-198. doi:10.1177/019027250707000207.

Collins, P. Y., Patel, V., Joestl, S. S., March, D., Insel, T. R., Daar, A. S. \& Stein, D. J. (2011). Grand challenges in global mental health. Nature. 6, 27-30. doi:10.1038/475027a.

Ellis, B. (2004). Timing of Pubertal Maturation in Girls: An integrated life history approach. Psychological Bulletin, 130, 920-958. doi:10.1037/0033-2909.130.6.920.

Fitzsimmons, E. E. \& Bardone-Cone, A. M. (2010). Differences in coping across stages of recovery from an eating disorder. International Journal of Eating Disorders, 43, 689-693. doi:10.1002/eat.20781.

Frydenberg, E. \& Lewis, R. (1997). Escalas de afrontamiento para adolescentes [Adolescent Coping Scale] (ACS). Madrid: TEA ediciones.

Fryer, S., Waller, G. \& Kroese, B. (1997). Stress, Coping, and Disturbed Eating Attitudes in Teenage Girls. International Journal of Eating Disorders, 22, 427-436. doi:10.1002/(SICI)1098108X(199712)22:4<427::AID-EAT8>3.0.CO;2-O.

García-Grau, E., Fusté, A., Miró, A., Saldaña, C. \& Bados, A. (2002). Coping style and disturbed eating attitudes in adolescent girls. International Journal of Eating Disorders, 32, 116-120. doi:10.1002/eat.10060.

García-Grau, E., Fusté, A., Miró, A., Saldaña, C. \& Bados, A. (2004). Coping style and vulnerability to Eating Disorders in Adolescent Boys. European Eating Disorders Review, 12, 61-67. doi:10.1002/erv.550.

García-Grau, E., Fusté, A., Mas, N., Gómez, J., Bados, A. \& Saldaña, C. (2010). Dimensionality of three versions of the Eating Disorder Inventory in adolescent girls. European Eating Disorders Review, 18 , 318-327. doi:10.1002/erv.995.

Garner, D.M. (2010). Inventario de Trastornos de la Conducta Alimentaria-3 [Eating Disorders Inventory-3] (EDI-3). Madrid: TEA Ediciones.

Graber, J. A., Brooks-Gunn, J., Paikoff, R. L. \& Warren, M.P. (1994). Prediction to eating problems: An 8-year study of adolescent girls. Developmental Psychology, 30, 823-834. doi:10.1037/0012-1649.30.6.823.
Halvarsson-Edlund, K., Sjödén, P. O. \& Lunner, K. (2008). Prediction of disturbed eating attitudes in adolescent girls: A 3-year longitudinal study of eating patterns, self-esteem and coping. Eating and Weight Disorders, 13, 87-94

Hasking, P. A. (2006). Reinforcement sensitivity, coping, disordered eating and drinking behavior in adolescents. Personality and individual differences, 40, 677-688. doi:10.1016/j.paid.2005.07.017.

Hernández-Cortés, L. M. \& Londoño, C. (2013). Imagen corporal, IMC, afrontamiento, depresión y riesgo de TCA en jóvenes universitarios. Anales de Psicología, 29, 748-761. doi: 10.6018/analesps.29.3.175711.

Huon, G., Hayne, A., Gunewardene, A., Strong, K., Lunn, N., Piisa, T. \& Lim, J. (1999). Accounting for Differences in Dieting Status: Steps in the Refinement of a Model. International Journal of Eating Disorders, 26, 420-433. doi:10.1002/(SICI)1098-108X(199912)26:4<420::AIDEAT8 $>3.0 . \mathrm{CO} ; 2-\mathrm{G}$

Kardoff, E. \& Ohbrecht, H. (2008). Overweight, obesity and eating disorders in adolescents- a socio-somatic reaction to social change? Journal of Public Health, 16, 429-438. doi:10.1007/s10389-008-0192-y.

Lee, J. M., Greening, L. \& Stoppelbein, L. (2007). The moderating effect of avoidant coping on restrained eaters' risk for disinhibited eating: implications for dietary relapse prevention. Behaviour Research and Therapy, 45, 2334-48. doi:10.1016/j.brat.2007.03.010.

Lobera, I. J., Estébanez, S., Fernández, M. J. S., Bautista, E. Á. \& Garrido, O. (2009). Coping strategies in eating disorders. European Eating Disorders Review, 17, 220-226. doi:10.1002/erv.920.

López-Guimerà, G., Neumark-Sztainer, D., Hannan, P., Fauquet, J., Loth, K. \& Sánchez-Carracedo, D. (2012). Unhealthy Weight-Control Behaviours, Dieting and Weight Status: A Cross-cultural Comparison between North American and Spanish Adolescents. European Eating Disorders Review. doi:10.1002/erv.2206.

Moreno, C., Muñoz-Tinoco, V., Pérez, P., Sánchez-Queija, I., Granado M.C., Ramos, P. \& Rivera, F. (2008). Desarrollo adolescente y salud. Resultados del Estudio HBSC-2006 con chicos y chicas españoles de 11 a 17 años. [Adolescent development and health. Results of the HBSC2006 study with spanish boys and girls from 11 to 17 years old]. Madrid: Ministerio de Sanidad, Política Social e Igualdad. NIPO: 351-08-036-0.

Moreno, M. A. \& Ortiz, G.R. (2009). Trastorno Alimentario y su relación con la imagen corporal y la autoestima en adolescentes. Terapia Psicológica, 27, 181-190. doi: 10.4067/S0718-48082009000200004.

OMS (1999). Programación para la Salud y el Desarrollo de los Adolescentes. [Programming for Adolescent Health and Development]. Ginebra. Serie de Informes Técnicos, 886.

OMS (2004). Prevención de los trastornos mentales: intervenciones efectivas y opciones de políticas: informe compendiado. [Prevention of mental disorders. Effective interventions and policy options]. Organización Mundial de la Salud: Ginebra.

OMS (2011). Evidence for gender responsive actions to promote mental health. Young people's health as a whole-of-society response. Copenhagen, WHO Regional Office for Europe, 2011.

OMS (2012a). Social determinants of health and well-being among young people. Health Behaviour in School-Aged Children (HBSC) study: international report from the 2009/2010 survey. Copenhagen, WHO Regional Office for Europe, 2012 (Health Policy for Children and Adolescents, No. 6).

OMS (2012b). Evidence for gender responsive actions to prevent and manage injuries and substance abuse. Young people's health as a wholeof-society response. Copenhagen, WHO Regional Office for Europe.

Pamies, L. \& Quiles, Y. (2012). Estrategias de afrontamiento evitativas y riesgo de desarrollar un trastorno de la conducta alimentaria en adolescentes. [Avoidant coping styles and risk of developing an eating disorder in adolescents]. Psicothema, 24, 230-235.

Sierra, S. \& Lemos, S. (2008). Examining the Relationship between Binge Eating and Coping Strategies and the Definition of Binge Eating in a Sample of Spanish Adolescents. The spanish Journal of Psychology, $11,172-180$

Sierra-Baigrie, S., Lemos-Giráldez, S., Paino, M. \& Fonseca-Pedrero, E. (2012). Exploring the Relationship between Coping Strategies and 
Binge Eating in Nonclinical Adolescents. European Eating Disorders Review, 20, e63-e69. doi:10.1002/erv.1103.

Sim, L. \& Zeman, J. (2006). The Contribution of Emotion Regulation to Body Dissatisfaction and Disordered Eating in Early Adolescent Girls. Journal of Youth and Adolescence, 35, 219-228. doi:10.1007/ s10964-005-9003-8.

Simes, R. J. (1986). An improved Bonferroni procedure for multiple test of significance. Biometrika, 73, 751-754.

Smolak, L., Levine, M. P. \& Gralen, S. (1993). The impact of puberty and dating on eating problems among middle school girls. Journal of Youth and Adolescence, 22, 355-368. doi:10.1007/BF01537718.

Stice, E., Shaw, H. \& Marti, C.N. (2007). A Meta-Analytic Review of Eating Disorder Prevention Programs: Encouraging Findings. Annual Review of Clinical Psychology, 3, 207-231. doi:10.1146/annurev. clinpsy.3.022806.091447.

Swarr, A. \& Richards, M. (1996). Longitudinal Effects of Adolescent Girls' Pubertal Development, Perceptions of Pubertal Timing, and Parental Relations on Eating Problems. Developmental Psychology, 32, 636-646. doi:10.1037/0012-1649.32.4.636.

Tang, C., Yeung, D. \& Lee, A. (2003). Psychological correlates of emotional responses to menarche among Chinese adolescent girls. Journal of adolescent health, 33, 193-2001. doi:10.1016/S1054-139X(03)00049-1.

Tanti, C., Stukas, A., Halloran, M. \& Foody, M. (2011). Social identity change: Shifts in social identity during adolescence. Journal of Adolescence, 34, 555-567. doi:10.1016/j.adolescence.2010.05.012.

UNICEF (2011). Estado mundial de la infancia 2011. La Adolescencia: una época de oportunidades. [The State of the World's Children 2011: Adolescence - An Age of Opportunity]. Nueva York: Fondo de las Naciones Unidas para la Infancia.

Yager, Z. \& O'dea, J. (2008). Prevention programs for body image and eating disorders on University campuses: a review of large, controlled interventions. Health Promotion International, 23, 173-189. doi:10.1093/heapro/dan004. 